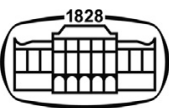

AKADÉMIAI KIADÓ

Journal of Psychedelic Studies

5 (2021) 1, 9-16

DOI:

$10.1556 / 2054.2021 .00157$

(c) 2021 The Author(s)

\title{
Exploring the relationship between microdosing, personality and emotional insight: A prospective study
}

\section{HANNAH M. DRESSLER ${ }^{1}$ (D), STEPHEN J. BRIGHT ${ }^{2}$ (1) and VINCE POLITO ${ }^{3 *}$ (1)}

\author{
${ }^{1}$ Georg Elias Mueller Institute of Psychology, University of Göttingen, Goßlerstraße 14, 37073 \\ Göttingen, Germany \\ ${ }^{2}$ School of Medical and Health Sciences, Edith Cowan University, Joondalup, WA, 6027, Australia \\ ${ }^{3}$ Department of Cognitive Science, Macquarie University, NSW, 2109, Australia
}

Received: October 24, 2020 • Accepted: February 22, 2021

Published online: March 24, 2021
ORIGINAL RESEARCH PAPER

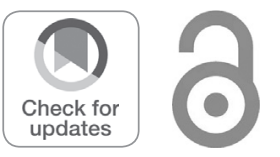

*Corresponding author. Tel.: +612 98502966.

E-mail: vince.polito@mq.edu.au

\begin{abstract}
Backround and aims: Having entered the recent public and research zeitgeist, microdosing involves consuming sub-perceptual doses of psychedelic drugs, allegedly to enhance performance, creativity, and wellbeing. The results of research to date have been mixed. Whereas most studies have reported positive impacts of microdosing, some microdosers have also reported adverse effects. In addition, research to date has revealed inconsistent patterns of change in personality traits. This prospective study explored the relationship between microdosing, personality change, and emotional awareness. Methods: Measures of personality and alexithymia were collected at two time points. 76 microdosers participated at baseline. Invitations to a follow-up survey were sent out after 31 days, and 24 participants were retained. Results: Conscientiousness increased, while neuroticism decreased across these time points $(n=24)$. At baseline $(N=76)$, neuroticism was associated with alexithymia. In addition, neuroticism correlated negatively with duration of prior microdosing experience, and extraversion correlated positively with both duration of prior microdosing experience and lifetime number of microdoses. Conclusion: These results suggest that microdosing might have an impact on otherwise stable personality traits.
\end{abstract}

\section{KEYWORDS}

microdosing, psychedelics, alexithymia, neuroticism, five-factor model of personality, mental health

\section{INTRODUCTION}

There has been recent growing public awareness about the phenomenon of "microdosing", with stories featured in Vogue (Mechling, 2017), Forbes (Williams, 2017), The New York Times (Glatter, 2015) and the Australian Financial Review (Valentish, 2018). Microdosing involves taking small quantities of psychedelic substances at regular or semi-regular intervals with the intention to improve psychological wellbeing, work performance and/or creativity (Fadiman, 2011). Classic psychedelic substances, such as lysergic acid diethylamide (LSD), psilocybin and mescaline, act (at least partially) by binding to the 2A subtype of 5-hydroxytryptamine receptors in the brain where they act as agonists (Nichols, 2016). Consumption of recreational doses of psychedelic substances is usually associated with an alteration of consciousness. Such consumption often leads to changes in visual and auditory perception. Microdoses are considered subperceptual doses, usually ranging from 1/20 to $1 /$ 10 of a recreational, psychoactive dose (Kuypers et al., 2019). Ideally, such subperceptual doses should not result in visual effects (Fadiman, 2011) or a marked change in consciousness (Johnstad, 2018). 
LSD and psilocybin are the most common psychedelics reportedly microdosed (Anderson et al., 2019), so a typical microdose might be considered between 4 and $20 \mu \mathrm{g}$ of LSD or between 0.1 and $0.6 \mathrm{~g}$ of dried psilocybin mushrooms (Lea, Amada, \& Jungaberle, 2019). According to microdosers' selfreports, there is individual variance in the optimal dose required to obtain the intended effects while remaining subperceptual (Hupli, Berning, Zhuparris, \& Fadiman, 2019). Most microdosers reportedly adjust their initial dose through trial and error (Lea et al., 2019). While various microdosing regimens have been identified by Lea, Amada, Jungaberle, Schecke and Klein (2020), most people reported microdosing between once and a few times a week, usually in the morning and as a cyclic activity (e.g., every third day). According to Johnstad (2018), most experienced microdosers restricted their use to phases lasting from a few weeks to a few months, as some users believe that microdoses may not provide benefits when used for long durations.

Although acute effects of microdosing have been found to be subtle in clinical trials (Bershad, Schepers, Bremmer, Lee, \& Wit, 2019; Ramaekers et al., 2020; Yanakieva et al., 2018), proponents claim that regular microdosing can lead to a range of long-term benefits, such as improved mood, wellbeing, sociability, creativity and performance (Webb, Copes, \& Hendricks, 2019). Andersson and Kjellgren's (2019) thematic analysis of 32 microdosing videos on the Youtube platform aimed to understand microdosers' experiences, expectations, approaches, and viewpoints. They found claims that microdosing led to a facilitation of self-reflection and personal insights. Meanwhile, people who engage in microdosing primarily to address an existing mental health issue have reported they do it to self-treat depression, (social) anxiety, suicidality, addiction, trauma, intrusive thoughts, and chronic pain (Petranker, Kim, \& Anderson, 2020).

Although psychedelic microdosing has been growing in popularity (Anderson et al., 2019; Hupli et al., 2019), Fadiman (2011) acknowledged that the practice likely has roots going back to indigenous cultures and healers who likely "systematically and fully explored every dose level" (p. 210). He further recognized that modern psychedelic research had often overlooked these subperceptual doses.

Following a 30-year embargo on psychedelic research (Strauss, Bright, \& Williams, 2016), there has been a recent resurgence of scientific interest in the therapeutic and medicinal effects of psychedelic substances, often referred to as the psychedelic renaissance (Bright \& Williams, 2018). Contemporary clinical research on higher doses of psychedelics has shown that LSD administered in a supportive setting increases optimism in healthy subjects (CarhartHarris et al., 2016). High doses of psilocybin decreased depressive and anxious symptoms in patients with lifethreatening cancer diagnoses (Griffiths et al., 2016) and promoted abstinence in patients with alcohol (Bogenschutz et al., 2015) and tobacco addiction (Garcia-Romeu, Johnson, \& Griffiths, 2014). However, contemporary microdosing research remains limited.

To date, few placebo-controlled, randomized, doubleblind studies have investigated the effects of microdosing
LSD on mood, perception and cognition. Yanakieva et al. (2018) observed changes in time perception following LSD microdosing. Bershad et al. (2019) observed a dose-related subjective sensitivity to drug effects, and an increase in ratings of vigor at $26 \mu \mathrm{g}$ of LSD. Ramaekers et al. (2020) observed a significant increase in pain tolerance and decreased pain perception, which was significant at doses of $20 \mu \mathrm{g}$ of LSD. Family et al. (2020) found no adverse effects from 5 to $20 \mu \mathrm{g}$ LSD but no marked cognitive changes. In contrast, Hutten et al. (2020) found that low doses of LSD (5-20 $\mu \mathrm{g})$ increased positive mood, friendliness, arousal, and decreased attentional lapses. However, increases in anxiety and confusion were also observed. Finally, Holze et al. (2020) found that the threshold-dose for subjective drug effects was at $10 \mu \mathrm{g}$ of LSD.

A non-blinded experimental study by Prochazkova et al. (2018) examined the cognitive-enhancing potential of microdosing psilocybin-containing truffles in a naturalistic setting. Microdosers were found to have significantly increased performance in convergent and divergent thinking after a non-blinded microdose.

\section{Microdosing and personality}

Polito and Stevenson (2019) were the first researchers to systematically investigate the long-term effects of microdosing psychedelics by tracking the experiences of microdosers $(N=63)$ over a six-week period. Participants filled out daily reports and completed a comprehensive questionnaire battery at baseline and the end of the study. The results of this prospective study suggested that microdosing led to improved mental health (decreased depression and stress) and to improved attentional capacities (decreased mind wandering and increased levels of absorption). In addition, a small but significant increase of the personality trait neuroticism was observed. Neuroticism is a person's tendency to experience negative emotions more easily and has been described as emotional instability. Personality traits such as neuroticism are considered relatively stable constructs and typically not expected to alter over a short period of time. Differences in personality between microdosers and controls have also been found in the trait openness; however, to date this has only been reported in cross-sectional designs, so it is unclear if microdosing is the cause of these differences (Anderson et al., 2019; Bright, Gringart, Blatchford, \& Bettinson, 2021).

The increase in the personality trait neuroticism observed by Polito and Stevenson (2019) appears to contradict the finding that people who microdose tend to have improved mental health, observed by Polito and Stevenson and others (Anderson et al., 2019; Fadiman, 2011; Webb et al., 2019). However, Bright et al. (2021) found that microdosers had higher levels of depression and anxiety compared to a yoga control group. In a recent review of 14 microdosing studies, Kuypers (2020) observed that "while low LSD doses were experienced as pleasant, it was also shown that drug disliking and anxiety increased, and that a cycling pattern of depressive and euphoric mood changes can occur" (Kuypers, 2020, pp. 9-10). Andersson and 
Kjellgren (2019) observed increased negative emotion among microdosers, proposing increased emotional awareness may initially trigger negative emotions, but also provide "more insights and possibilities to work through personal issues" (Unwanted effects and lack of results, para. 2). Similarly, Polito and Stevenson (2019) suggested that reduced mind wandering and increased absorption in immediate experiences might assist participants to identify and process both negative and positive emotions, leading to more emotionally intense experiences.

Our study aimed to further understand the relationship between microdosing, changes in personality over time and emotional awareness. Personality can be assessed by using the five-factor model of personality, where each of the factors (extraversion, agreeableness, conscientiousness, neuroticism and openness) represents a distinct personality trait (Costa \& McCrae, 1992). Extraversion describes the sociability of an individual. An extroverted person might be more talkative in social settings or get excited more easily. Agreeableness reflects the degree to which a person may be altruistic, cooperative and trust others. Conscientiousness represents the determination and self-control of an individual. Individuals who score high on this scale are typically considered reliable, responsible and organized. Openness reflects someone's interest in new experiences and impressions.

Although not a classic personality trait, another individual difference characteristic that may shape the experience of microdosers is alexithymia. Alexithymia represents a person's emotional literacy and is an indicator of emotional insight. In particular, alexithymia reflects a difficulty in identifying, describing and expressing one's feelings (Bagby, Parker, \& Taylor, 1994).

\section{Research questions}

1. Does microdosing lead to changes in self-reported personality traits?

2. Is an individual's level of prior microdosing experience related to self-reported personality traits?

3. Are emotional insight and neuroticism associated in people who microdose?

4. Does emotional insight predict further increases in neuroticism among people who microdose?

\section{METHODS}

Data were collected at two time points using a prospective within-subject design. There was a minimum interval of 31 days between Time 1 (T1) and Time 2 (T2) to ensure that self-reported microdosers would be able to have multiple dosing sessions between the time points.

\section{Participants}

Participants were recruited through announcements on webpages, newsletters and the social media of non-profit psychedelic organizations (e.g. PRISM Australia, the MIND Foundation, the OPEN Foundation, the Third Wave, microdosing.nl). Additional recruiting strategies included posts in psychedelic Facebook groups and online discussion forums (e.g., the microdosing subreddit on reddit.com).

Recruitment occurred between October 2019 and April 2020. Participants were asked to only participate if they were 18 years or older, fluent in English, and had past and current experience with microdosing. Participants with a current mental health or neurological diagnosis, a current substance use disorder or a history of psychosis were asked to not participate.

Ninety participants submitted complete responses at T1. After a minimum waiting period of 31 days, 32 participants responded to an invitation to complete the followup survey at T2, of which 28 participants submitted complete responses. Participants were excluded from the analysis if they: were not current microdosers $(n=4)$; microdosed a substance not considered a psychedelic $(n=$ $2)$; reported dosing amounts typically considered a recreational dose (e.g., $75-100 \mathrm{mcg}$ of LSD $[n=5]$ ); reported very high (non-psychedelic) drug use $(n=5)$. Finally, one participant reported using medication for depression during the course of the study and was excluded. Exclusion of these participants led to 76 responses for $\mathrm{T} 1$ and 24 responses for $\mathrm{T} 1$ and $\mathrm{T} 2$.

Participants $(N=76)$ were aged between 18 and 68 years $(M=33.0$ years; $S D=13.1) .61$ participants were male (80.3\%), 14 were female (18.4\%) and $1(1.3 \%)$ self-classified as "Other". Participants reported residing in North America (50\%), Europe (34.2\%), Australia or New Zealand (10.5\%), Asia (2.6\%), South Africa (1.3\%), and Central America (1.3\%). Participants who completed both parts of the survey $(n=24)$ were also aged $18-68$ years $(M=33.3$ years; $S D=$ 11.8). The ratio between males (79.2\%) and females (20.8\%) was similar to the $\mathrm{T} 1$ sample, and participants reported residing in similar countries.

\section{Procedure}

Potential participants were directed to the study webpage, hosted on the Qualtrics platform. Participants who chose to begin the survey were asked to create an anonymous e-mail address. Instructions explaining how to do this were provided. To secure participants' anonymity, they were asked to use an unidentifiable name. Participants then completed the online survey at $\mathrm{T} 1$, which included: the completion of the substance use disorder screening tool 'Modified ASSIST'; the M5-50 Personality Questionnaire; and the 20-Item Toronto Alexithymia Scale (TAS-20). Participants also provided basic demographic information and answered questions about their microdosing behavior (e.g., type of substance consumed; primary motivation for microdosing).

31 days after survey completion, an invitation link to a follow-up survey was sent to the anonymous e-mail addresses of participants. Participants who did not respond to the follow-up survey at $\mathrm{T} 2$ were sent a second reminder after another 14 days. The M5-50 Personality Questionnaire and TAS-20 were re-administered at T2. 
The surveys took about 15 minutes to complete and there was no incentive for participation. Ethical approval was provided by the Ethics Committee of the Georg-Elias-MüllerInstitute of Psychology (Application number 2019/232).

\section{Materials}

Modified version of the alcohol, smoking and substance involvement screening test (World Health Organization, 2010). Developed by the World Health Organization, the Alcohol, Smoking and Substance Involvement Screening Test (ASSIST) was designed to detect risky and harmful substance use behavior, in addition to dependence. It is usually administered in primary healthcare settings. The ASSIST has demonstrated good reliability and feasibility, and good concurrent, construct, predictive and discriminant validity (World Health Organization, 2010). We used a modified version of the ASSIST consisting of 7 items, which collect information about the types of drugs ever used and their frequency of consumption. Follow up items are asked to assess for hazardous use, harmful use, and dependence (e.g., "During the past three months, how often have you failed to do what was normally expected of you because of your use of [first drug, second drug, etc.]?"). The modified version asked about the frequency of substance use within the last year and social difficulties associated with substance use within the past three months. An 8th item, concerning injected substance use, was omitted. Ratings of frequency (e.g. "Never", "Daily or almost daily") were scored from 0 to 6 and an overall score was calculated. Any participant who had used a drug within the last three months and exceeded a total score of 27 for that drug was excluded from the analysis due to very high (non-psychedelic) substance use.

M5-50 Personality questionnaire (Socha, Cooper, \& Mccord, 2010). The M5-50 Personality Questionnaire is a measure of the personality domains extraversion, agreeableness, conscientiousness, neuroticism and openness to experience.

The questionnaire consists of 50 items with 10 items for each subscale, taken from Goldberg's International Personality Item Pool (Socha et al., 2010). The M5-50 Personality Questionnaire was designed as a short form of Costa and McCrae's (1992) NEO-PI-R (Socha et al., 2010). A five-point Likert-type scale is used to rate level of agreement with each item, with scores ranging from 1 (Inaccurate) to 5 (Accurate). The measure has been shown to have good reliability and a reasonably good model fit (Socha et al., 2010).

20-Item toronto alexithymia scale (TAS-20; Bagby et al., 1994). The TAS-20 is a 20 -item measure of alexithymia. Questions focus on difficulties identifying feelings, difficulties describing feelings, and externally oriented thinking. Participants rate their level of agreement with each statement on a five-point Likert scale. The overall scale has demonstrated good internal consistency and a good testretest reliability (Bagby et al., 1994).

During the analysis, it was discovered that due to an administrative error, Item 2 of the TAS-20 had been phrased
Table 1. Substances consumed for microdosing

\begin{tabular}{lccc}
\hline & \multicolumn{3}{c}{ Microdosing substance } \\
\cline { 2 - 4 } & Psilocybin & LSD & Other \\
\hline Participants T1 $(N=76)$ & $48.7 \%$ & $36.8 \%$ & $14.5 \%$ \\
Participants T1 and T2 $(n=24)$ & $45.8 \%$ & $37.5 \%$ & $16.7 \%$ \\
\hline
\end{tabular}

incorrectly and so this item was omitted from all calculations.

\section{RESULTS}

Participants consumed between 3 and 30 microdoses during the study period $(M=11.3$ microdoses; $S D=7.53)$. As can be seen in Table 1, the majority of participants reported microdosing psilocybin or LSD. Specifically, 33 participants reported microdosing with psilocybin (Dose $M=0.367 \mathrm{~g}$, $S D=0.503)$, and 23 participants reported microdosing with LSD (Dose $M=15.3 \mu \mathrm{g}, S D=6.27$ ). There were an additional 4 psilocybin microdosers and an additional 5 LSD microdosers who did not provide clear information on their typical dose. Finally, 11 participants reported microdosing a range of other substances including $1 \mathrm{P}-\mathrm{LSD} / 1 \mathrm{cP}-\mathrm{LSD}$, Ibogaine, DMT, 4-HO-MET, 4-AcO-MET, ALD-52, 25-I, and BOD. As can be seen in Table 2, the primary motives were Personal Growth and Self Medication. A smaller number of participants reported microdosing primarily to Increase Productivity, Curiosity or to Increase Creativity. Specified text-responses of participants coded as "Other", revealed that their motives were typically a combination of motives outlined above. As can be seen in Tables 1 and 2, participants' reported substance and motive were relatively consistent at $\mathrm{T} 1$ and $\mathrm{T} 2$.

Alpha was set at 0.05 for all analyses, parametric inferential statistics were used for all analyses, and assumptions were met unless stated otherwise.

To explore whether any of the personality traits changed over time, five two-tailed, simple paired t-tests were conducted comparing mean scores of T1 against mean scores of T2. As can be seen in Table 3, conscientiousness significantly increased $(n=24, t=-2.26, P=0.034, d=-0.460)$, while neuroticism significantly decreased $(n=24, t=3.26, P=$ $0.003, d=0.666$ ). There was no change in extraversion, agreeableness, or openness.

We also investigated whether prior microdosing experience (indexed by total lifetime doses, and number of months since first microdose) correlated with any personality traits at T1. Both indicators of prior experience were not normally distributed in our sample, so the Spearman correlation was used. Based on the responses of all 76 participants at T1, a negative correlation was found between prior experience in months and neuroticism $(r=-0.237, P=0.039)$, though not with participants' lifetime number of microdoses. Extraversion correlated positively with prior experience in months $(r=0.228, P=0.047)$ and also 
Table 2. Primary microdosing motive

\begin{tabular}{|c|c|c|c|c|c|c|}
\hline & \multicolumn{6}{|c|}{ Primary motive } \\
\hline & Self-medication & Personal growth & Increase productivity & Increase creativity & Curiosity & Other \\
\hline Participants T1 $(N=76)$ & $23.7 \%$ & $46.1 \%$ & $9.2 \%$ & $1.3 \%$ & $3.9 \%$ & $15.8 \%$ \\
\hline Participants T1 and T2 $(n=24)$ & $25 \%$ & $41.7 \%$ & $12.5 \%$ & - & $4.2 \%$ & $16.7 \%$ \\
\hline
\end{tabular}

Table 3. General changes in personality

\begin{tabular}{|c|c|c|c|c|c|c|c|}
\hline \multirow{2}{*}{ Personality trait } & \multicolumn{2}{|c|}{ Time 1} & \multicolumn{2}{|c|}{ Time 2} & \multirow{2}{*}{$t$} & \multirow{2}{*}{$P$} & \multirow{2}{*}{$d$} \\
\hline & $M$ & $S D$ & $M$ & $S D$ & & & \\
\hline Agreeableness & 3.73 & 0.504 & 3.89 & 0.295 & -1.82 & 0.082 & -0.371 \\
\hline Conscientiousness & 3.45 & 0.647 & 3.67 & 0.600 & -2.26 & $0.034^{\star}$ & -0.460 \\
\hline Extraversion & 2.95 & 0.828 & 3.18 & 0.711 & -2.04 & 0.053 & -0.415 \\
\hline Neuroticism & 2.69 & 0.954 & 2.13 & 0.502 & 3.26 & $0.003^{* *}$ & 0.666 \\
\hline Openness & 4.13 & 0.459 & 4.20 & 0.402 & -1.22 & 0.236 & -0.249 \\
\hline
\end{tabular}

${ }^{*} P<0.05,{ }^{* *} P<0.01$, two-tailed.

with participants' lifetime number of microdoses $(r=$ $0.262, P=0.022$ ).

The relationship between emotional insightfulness and the personality trait neuroticism was explored by examining Pearson's correlation between alexithymia at T1 and neuroticism at $\mathrm{T} 1$. There was a significant positive association between alexithymia and neuroticism $(N=76, r=$ $0.526, P=<0.001)$. Finally, we investigated whether there was a relationship between alexithymia at baseline and changes in neuroticism over the course of the study using linear regression. Alexithymia at $\mathrm{T} 1$ was entered as the predictor, while the difference in neuroticism scores (Time 2 minus Time 1) was entered as the dependent variable. Alexithymia was not a significant predictor of the change in neuroticism $\left(n=24, P=0.077, R^{2}=0.135\right)$. Data for this study are available at https://osf.io/f9vr5/.

\section{DISCUSSION}

In the present study, we aimed to explore the relationship between microdosing, changes in personality over time, and alexithymia. After at least one month of microdosing, we observed significant increases in conscientiousness and decreases in neuroticism. Agreeableness, extraversion and openness were unaffected. Although alexithymia and neuroticism were positively correlated at $\mathrm{T} 1$, alexithymia did not predict neuroticism changes between T1 and T2. Extraversion was positively correlated with participants' number of lifetime doses and the duration of their prior microdosing experience. Neuroticism was negatively correlated with the duration of prior microdosing experience.

\section{Microdosing and personality}

Contrary to previous findings by Polito and Stevenson (2019), we observed a significant decrease in neuroticism.
The present finding appears more consistent with other contemporary microdosing research (Anderson et al., 2019; Webb et al., 2019) and many anecdotal reports highlighting the positive effects of microdosing on mental health, mood and (psychosocial) wellbeing (Fadiman, 2011; Waldman, 2018). Our finding is also more consistent with clinical research on higher psychedelic doses, in which the administration of oral psilocybin $(10 \mathrm{mg}$ and $25 \mathrm{mg}$, one week apart) has been linked to decreased neuroticism at a threemonth follow-up (Erritzoe et al., 2018).

One key difference between the present study and Polito and Stevenson's study is that the samples appear to differ in terms of their prior microdosing experience. The majority of Polito and Stevenson's participants (66.7\%) had microdosed 10 times or less, including a substantial portion (31.7\%) who had never microdosed before taking part in the study. By contrast, only $37.5 \%$ of participants in the current study had microdosed 10 times or less, and all our participants reported at least some prior microdosing experience. As previously discussed, research by Andersson and Kjellgren (2019) suggests that microdosing may initially trigger negative emotions, which in turn provides opportunities to address personal issues. Polito and Stevenson's sample contained mainly participants who were microdosing naive when entering the study or still in an early phase of their microdosing experience. The initial phase of microdosing may have increased awareness of unaddressed (negative) emotions, leading to increased scores in neuroticism. Participants in the current sample, due to relatively greater prior exposure to microdosing, may have learned to process and integrate their emotions better. This interpretation is supported by the negative correlation between prior microdosing experience and neuroticism at T1. Longer term microdosing might actually reduce rather than increase neuroticism. However, it is also possible that microdosers who demonstrate larger decreases in neuroticism are more likely to engage in long-term microdosing. 
Conscientiousness significantly increased in our sample, suggesting that participants perceived themselves as more organized, responsible and determined after microdosing. Microdosers might be able to complete their daily tasks with more focus, resulting in more reliable and organized behavior. The increase in conscientiousness is consistent with Andersson and Kjellgren's (2019) findings, where microdosers reported "less procrastination and a spontaneous impulse to clean the house, tidy drawers, pay bills, or address other postponed or neglected tasks" (Insights and transformation section, para.3). The present finding is also consistent with research on higher psilocybin doses by Erritzoe et al. (2018), who observed a trend toward increased conscientiousness at a 3-month follow-up.

We observed no significant change in extraversion, agreeableness, or openness from T1 to T2 (although there was a trend toward increased extraversion, $P=0.053$ ). Extraversion was also positively correlated with prior microdosing experience. This suggests that extroverted individuals may be more likely to engage in long-term microdosing. Findings from high-dose psychedelic research have shown that ingestion of psilocybin has led to persistent increases in openness (Erritzoe et al., 2018; Maclean, Johnson, \& Griffiths, 2011). Similarly, in research with cross-sectional designs (Anderson et al., 2019; Bright et al., 2021), microdosers have been found to score higher in openness compared to non-microdosing controls. The null finding related to openness in the current study suggests that rather than microdosing increasing openness, it may be that people already high in openness are more likely to try microdosing.

\section{Alexithymia}

Alexithymia and neuroticism were positively correlated at $\mathrm{T} 1$, demonstrating that emotional insightfulness may be associated with lower neuroticism among microdosers. These findings are consistent with previous research that has found relationships between neuroticism and alexithymia in healthy Italian graduate students (Messina, Fogliani, \& Paradiso, 2010), parents of daughters with eating disorders (Espina, 2003), and in subjects with medically unexplained physical symptoms (Gucht, Fischler, \& Heiser, 2004). These diverse findings indicate that emotional insightfulness may generally be associated with lower neuroticism.

In the current study alexithymia at $\mathrm{T} 1 \mathrm{did}$ not predict subsequent neuroticism change. However, the negative correlation between prior microdosing experience and neuroticism suggests that more experienced participants may have learned to integrate their emotional insights.

\section{Limitations and future directions}

There are several limitations to the study design. Due to practical and legal restrictions, our study was not dose or placebo controlled. Participants microdosed a range of substances and differed in dosing amounts and their frequency of consumption. Although this allowed an examination of microdosing in a naturalistic setting, this study was not as precise as a controlled experiment with predetermined dosing amounts, fixed schedules, and a placebo-control condition.

Participants were recruited worldwide and through a wide range of psychedelic organizations and forums. However, the survey was carried out in English, making it inaccessible for non-English speaking microdosers. Due to ethical restrictions of this study, we were not able to recruit participants with a current mental health diagnosis or substance use disorder. This exclusion criterion limits the generalizability of our sample. Only $23.7 \%$ of participants selected Self-Medication as their primary motive; the number of people engaging in microdosing with this motive is likely to be higher in the general population. In addition, there could have been sampling bias, leading to an over-representation of participants who had mainly positive experiences with psychedelics. Finally, most participants reportedly engaged at least once in recreational drug use while microdosing (excluding alcoholic beverages and tobacco products), making it difficult to be certain that effects found are entirely due to microdosing. Other observational studies have also found that microdosers often report past experience with, or recent use of, recreational drugs (Anderson et al., 2019; Johnstad, 2018; Lea, Amada, Jungaberle, Schecke, Scherbaum \& Klein, 2020; Rosenbaum et al., 2020; Webb et al., 2019), presenting a common limitation in studies of microdosing in naturalistic settings. For this reason, the current findings should be interpreted with caution. Future research could build upon our exploratory findings by testing specified hypotheses regarding personality change in an experimental setting with a placebo control condition. Further, it will be important to untangle the effects of recreational psychedelic use by including psychedelic naïve microdosers.

\section{CONCLUSION}

Our results indicate that microdosing may impact personality traits. In this study a short course of microdosing led to increased conscientiousness. Contrary to earlier findings with mostly naive participants, we also found that neuroticism decreased in this sample of more experienced microdosers. In addition, prior microdosing experience correlated negatively with neuroticism and positively with extraversion. Finally, we found a negative association between emotional insight and neuroticism, although this was not predictive of future personality change. Future research could build upon these findings by investigating whether personality variables develop differently between microdosing naïve and experienced participants. The role of alexithymia could also be explored in microdosers with a current mental health diagnosis.

\section{REFERENCES}

Anderson, T., Petranker, R., Rosenbaum, D., Weissman, C. R., Dinh-Williams, L.-A., Hui, K., et al. (2019). Microdosing psychedelics: Personality, mental health, and creativity differences 
in microdosers. Psychopharmacology, 236(2), 731-740. https:// doi.org/10.1007/s00213-018-5106-2.

Andersson, M., \& Kjellgren, A. (2019). Twenty percent better with 20 micrograms? A qualitative study of psychedelic microdosing self-rapports and discussions on YouTube. Harm Reduction Journal, 16(1), 63. https://doi.org/10.1186/s12954-019-0333-3.

Bagby, R., Parker, J. D., \& Taylor, G. J. (1994). The twenty-item Toronto Alexithymia scale-I. Item selection and cross-validation of the factor structure. Journal of Psychosomatic Research, 38(1), 23-32. https://doi.org/10.1016/0022-3999(94)90005-1.

Bershad, A. K., Schepers, S. T., Bremmer, M. P., Lee, R., \& Wit, H. D. (2019). Acute subjective and behavioral effects of microdoses of lysergic acid diethylamide in healthy human volunteers. Biological Psychiatry, 86(10), 792-800. https://doi.org/10.1016/j. biopsych.2019.05.019.

Bogenschutz, M. P., Forcehimes, A. A., Pommy, J. A., Wilcox, C. E., Barbosa, P., \& Strassman, R. J. (2015). Psilocybin-assisted treatment for alcohol dependence: A proof-of-concept study. Journal of Psychopharmacology, 29(3), 289-299. https://doi.org/ 10.1177/0269881114565144.

Bright, S., Gringart, E., Blatchford, E., \& Bettinson, S. (2021). A quantitative exploration of the relationships between regular yoga practice, microdosing psychedelics, wellbeing and personality variables. Australian Journal of Psychology, 1-10. https://osf.io/zkpxe/.

Bright, S., \& Williams, M. (2018). Should Australian Psychology consider enhancing psychotherapeutic interventions with psychedelic drugs? A call for research. Australian Psychologist, 53(6), 467-476. https://doi.org/10.1111/ap.12345.

Carhart-Harris, R. L., Kaelen, M., Bolstridge, M., Williams, T. M., Williams, L. T., Underwood, R., et al. (2016). The paradoxical psychological effects of lysergic acid diethylamide (LSD). Psychological Medicine, 46(7), 1379-1390. https://doi.org/10.1017/ s0033291715002901.

Costa, P. T., \& McCrae, R. R. (1992). The five-factor model of personality and its relevance to personality disorders. Journal of Personality Disorders, 6(4), 343-359. https://doi.org/10.1521/ pedi.1992.6.4.343.

Erritzoe, D., Roseman, L., Nour, M. M., Maclean, K., Kaelen, M., Nutt, D. J., et al. (2018). Effects of psilocybin therapy on personality structure. Acta Psychiatrica Scandinavica, 138(5), 368378. https://doi.org/10.1111/acps.12904.

Espina, A. (2003). Alexithymia in parents of daughters with eating disorders. Journal of Psychosomatic Research, 55(6), 553-560. https://doi.org/10.1016/s0022-3999(03)00016-3.

Fadiman, J. (2011). The psychedelic explorer's guide: Safe, therapeutic, and sacred journeys. Park Street Press.

Family, N., Maillet, E. L., Williams, L. T. J., Krediet, E., CarhartHarris, R. L., Williams, T. M., et al. (2020). Safety, tolerability, pharmacokinetics, and pharmacodynamics of low dose lysergic acid diethylamide (LSD) in healthy older volunteers. Psychopharmacology, 237, 841-853. https://doi.org/10.1007/s00213019-05417-7.

Garcia-Romeu, A. P., Johnson, M. W., \& Griffiths, R. R. (2014). Examining the psychological mechanisms of psilocybin-assisted smoking cessation treatment: A pilot study. Drug and Alcohol Dependence, 140, e66. https://doi.org/10.1016/j.drugalcdep. 2014.02.200.
Glatter, R. (2015). LSD microdosing: The new job enhancer in silicon valley and beyond? Forbes. https://www.forbes.com/sites/ robertglatter/2015/11/27/lsd-microdosing-the-new-jobenhancer-in-silicon-valley-and-beyond/.

Griffiths, R. R., Johnson, M. W., Carducci, M. A., Umbricht, A., Richards, W. A., Richards, B. D., et al. (2016). Psilocybin produces substantial and sustained decreases in depression and anxiety in patients with life-threatening cancer: A randomized double-blind trial. Journal of Psychopharmacology, 30(12), 1181-1197. https://doi.org/10.1177/0269881116675513.

Gucht, V. D., Fischler, B., \& Heiser, W. (2004). Neuroticism, alexithymia, negative affect, and positive affect as determinants of medically unexplained symptoms. Personality and Individual Differences, 36(7), 1655-1667. https://doi.org/10.1016/j.paid. 2003.06.012.

Holze, F., Liechti, M. E., Hutten, N. R. P. W., Mason, N. L., Dolder, P. C., \& Theunissen, E. L., et al. (2020). Pharmacokinetics and pharmacodynamics of lysergic acid diethylamide microdoses in healthy participants. Clinical Pharmacology and Therapeutics, 109(3), 658666. https://doi.org/10.1002/cpt.2057.

Hupli, A., Berning, M., Zhuparris, A., \& Fadiman, J. (2019). Descriptive assemblage of psychedelic microdosing: Netnographic study of Youtube ${ }^{\mathrm{TM}}$ videos and on-going research projects. Performance Enhancement \& Health, 6(3-4), 129-138. https://doi.org/10.1016/j.peh.2019.01.001.

Hutten, N. R. P. W., Mason, N. L., Dolder, P. C., Theunissen, E. L., Holze, F., Liechti, M. E., et al. (2020). Mood and cognition after administration of low LSD doses in healthy volunteers: A placebo controlled dose-effect finding study. European Neuropsychopharmacology, 41, 81-91. https://doi.org/10.1016/j. euroneuro.2020.10.002.

Johnstad, P. G. (2018). Powerful substances in tiny amounts. Nordic Studies on Alcohol and Drugs, 35(1), 39-51. https://doi.org/10. $1177 / 1455072517753339$.

Kuypers, K. P. (2020). The therapeutic potential of microdosing psychedelics in depression. Therapeutic Advances in Psychopharmacology, 10, 1-15. https://doi.org/10.1177/ 2045125320950567.

Kuypers, K. P., Ng, L., Erritzoe, D., Knudsen, G. M., Nichols, C. D., Nichols, D. E., et al. (2019). Microdosing psychedelics: More questions than answers? An overview and suggestions for future research. Journal of Psychopharmacology, 33(9), 1039-1057. https://doi.org/10.1177/0269881119857204.

Lea, T., Amada, N., \& Jungaberle, H. (2019). Psychedelic microdosing: A subreddit analysis. Journal of Psychoactive Drugs, 52(2), 101-112. https://doi.org/10.1080/02791072.2019. 1683260 .

Lea, T., Amada, N., Jungaberle, H., Schecke, H., \& Klein, M. (2020). Microdosing psychedelics: Motivations, subjective effects and harm reduction. International Journal of Drug Policy, 75, 102600. https://doi.org/10.1016/j.drugpo.2019.11.008.

Lea, T., Amada, N., Jungaberle, H., Schecke, H., Scherbaum, N., \& Klein, M. (2020). Perceived outcomes of psychedelic microdosing as self-managed therapies for mental and substance use disorders. Psychopharmacology, 237(5), 1521-1532. https://doi. org/10.1007/s00213-020-05477-0.

Maclean, K. A., Johnson, M. W., \& Griffiths, R. R. (2011). Mystical experiences occasioned by the hallucinogen psilocybin lead to 
increases in the personality domain of openness. Journal of Psychopharmacology, 25(11), 1453-1461. https://doi.org/10. 1177/0269881111420188.

Mechling, L. (2017, May 25). Here's why microdosing with LSD isn't a fringe wellness movement. Vogue. https://www.vogue. $\mathrm{com} /$ article/microdosing-lsd-risks-benefits-mindfulnessdepression-ayelet-waldman.

Messina, A., Fogliani, A. M., \& Paradiso, S. (2010). Association between alexithymia, neuroticism, and social desirability scores among Italian graduate students. Psychological Reports, 107(1), 185-192. https://doi.org/10.2466/02.07.13.15.pr0.107. 4.185-192.

Nichols, D. E. (2016). Psychedelics. Pharmacological Reviews, 68(2), 264-355. https://doi.org/10.1124/pr.115.011478.

Petranker, R., Kim, J., \& Anderson, T. (2020, May 27). Microdosing as a response to the meaning crisis. Journal of Psychopharmacology. https://doi.org/10.31234/osf.io/2jnkf.

Polito, V., \& Stevenson, R. J. (2019). A systematic study of microdosing psychedelics. PloS One, 14(2), e0211023. https:// doi.org/10.1371/journal.pone.0211023.

Prochazkova, L., Lippelt, D. P., Colzato, L. S., Kuchar, M., Sjoerds, Z., \& Hommel, B. (2018). Exploring the effect of microdosing psychedelics on creativity in an open-label natural setting. Psychopharmacology, 235(12), 3401-3413. https://doi.org/10. 1007/s00213-018-5049-7.

Ramaekers, J. G., Hutten, N., Mason, N. L., Dolder, P., Theunissen, E. L., Holze, F., et al. (2020). A low dose of lysergic acid diethylamide decreases pain perception in healthy volunteers. Journal of Psychopharmacology. https://doi.org/10.1177/0269881120940937.

Rosenbaum, D., Weissman, C., Anderson, T., Petranker, R., DinhWilliams, L.-A., Hui, K., et al. (2020). Microdosing psychedelics: Demographics, practices, and psychiatric comorbidities.
Journal of Psychopharmacology, 34(6), 612-622. https://doi.org/ 10.1177/0269881120908004.

Socha, A., Cooper, C. A., \& Mccord, D. M. (2010). Confirmatory factor analysis of the M5-50: An implementation of the international personality item pool item set. Psychological Assessment, 22(1), 43-49. https://doi.org/10.1037/a0017371.

Strauss, N., Bright, S. J., \& Williams, M. L. (2016). Australia should be initiating a psychedelic research program: What are the barriers? Australian \& New Zealand Journal of Psychiatry, 50(11), 1036-1037. https://doi.org/10.1177/0004867416670520.

Valentish, J. (2018). Why professionals are taking psychedelic drugs in the workplace.Australian Financial Review. https://www.afr. $\mathrm{com} /$ life-and-luxury/arts-and-culture/why-professionals-aretaking-psychedelic-drugs-20181205-h18r0w.

Waldman, A. (2018). A really good day: How microdosing made a mega difference in my mood, my marriage, and my life. Anchor Books.

Webb, M., Copes, H., \& Hendricks, P. S. (2019). Narrative identity, rationality, and microdosing classic psychedelics. International Journal of Drug Policy, 70, 33-39. https://doi.org/10.1016/j. drugpo.2019.04.013.

Williams, A. (2017). How LSD saved one woman's marriage. The New York Times. https://www.nytimes.com/2017/01/07/style/ microdosing-lsd-ayelet-waldman-michael-chabon-marriage.html.

World Health Organization. (2010). ASSIST. World Health Organization. https://www.who.int/management-of-substance-use/ assist/.

Yanakieva, S., Polychroni, N., Family, N., Williams, L. T. J., Luke, D. P., \& Terhune, D. B. (2018). The effects of microdose LSD on time perception: A randomised, double-blind, placebocontrolled trial. Psychopharmacology, 236(4), 1159-1170. https://doi.org/10.1007/s00213-018-5119-x. 